\title{
Medicine and the Bomb
}

\section{Nuclear war: the medical facts}

\author{
JANE SMITH, TONY SMITH
}

\begin{abstract}
This is the first of four articles describing the physical, biological, and psychological consequences of nuclear explosions. Any prediction of the effects depends critically on what military strategists call the "scenario"-how many nuclear weapons might be used, how quickly, where they will fall, and at what height they may be detonated. Though we have used a range of possible examples to illustrate specific effects, we make no attempt to predict the numbers or types of weapons that might be used in any future war. Every major war this century confounded the military experts by turning out quite contrary to their expectations.
\end{abstract}

First and foremost, atomic weapons cause explosions. Some of the effects of a nuclear explosion are comparable to those of a conventional (chemical) explosion: the major differences are the possible magnitude of nuclear explosions-they can be much bigger-and the release of harmful nuclear radiation. Almost all the early deaths and destruction caused by nuclear weapons are due to blast and heat-because most people close enough to the centre of the explosion to receive a potentially lethal dose of the extremely harmful initial radiation will probably have been killed or fatally injured by the explosion itself.

The atomic bomb dropped on Hiroshima on 6 August 1945 had a power equivalent to 12500 tons of conventional explosive, TNT. It was exploded in the air 500 yards above the ground and killed about 65000 people either immediately or within a few weeks.

Modern strategic nuclear weapons are more powerful. A onemegaton bomb is equivalent to 1000000 tons of TNT; the total stock of nuclear weapons held by the United States and the USSR is estimated at around 10000 megatons-equivalent to around 800000 bombs of the Hiroshima size.

British Medical Journal, London WC1H 9JR

JANE SMITH, BA, staff editor

TONY SMITH, BM, BCH, deputy editor
The effect of a one-megaton explosion depends on whether it is exploded high in the air or close to the ground (fig 1). An explosion near enough to the ground to suck earth and building debris up into the stem of the mushroom cloud is known as a surface burst. Explosions high in the atmosphere-air bursts-do not produce this debris-filled mushroom. Regardless of height of burst, about $85 \%$ of the explosive energy of a nuclear fission weapon results in blast and heat. The remainder is produced as nuclear radiation- $5 \%$ initial (produced in a minute or so) and $10 \%$ as residual radiation emitted over a period of time.

An airburst at a height of 2000 yards produces an immensely hot, luminous fireball and a blast wave travelling at supersonic speed. When this wave hits the ground it is reflected, causing a secondary shock wave. These two waves fuse a little over one mile from the point vertically beneath the explosion (ground zero). The blast wave creates the greatest pressures around ground zero; as it travels outwards it gradually slows down and loses its force. Ten seconds after the explosion the shock wave is

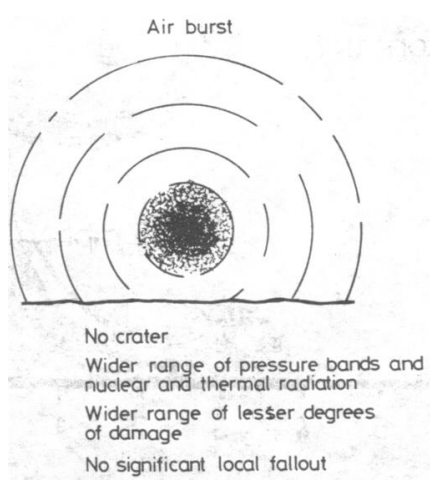

Surface burst

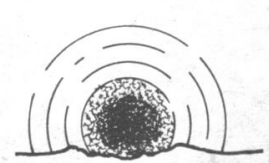

Crater

Greater pressure near ground zero Greater damage close to ground zero Range of thermal and nuclear radiation limited by buildings and hills Local fallout downwind of explosion

FIG 1-Difference between effects of nuclear weapons detonated in the air and near enough to the surface for the fireball to touch the ground. 
travelling at $180 \mathrm{mph}$ and has reached three miles from ground zero. Half a minute from the explosion this shock wave has spread to form a circle 20 miles in diameter; it is still travelling fast enough $(40 \mathrm{mph})$ to shatter all window glass in its path. The spread of thermal and nuclear radiation is greater from an air burst than from a ground explosion, though the spread may be reduced by the shielding effects of buildings or (as at Nagasaki) hills.

In a surface burst the fireball intersects with the earth's surface. The crater produced by a one-megaton bomb detonated actually on the ground is $300-400$ y wide and $50-80$ y deep. A 10-megaton bomb exploded at ground level on dry soil may cause a crater half a mile wide. Explosions near but not actually on the ground will produce smaller craters. The effects of a megaton bomb dropped on London may be estimated from published data and are shown in fig 2: such a bomb-relatively small by current standards-would destroy an area of central London about nine miles in diameter.

The height of an explosion above the ground greatly influences the type and amount of fallout generated. A genuine air

\section{8 seconds after detonation}
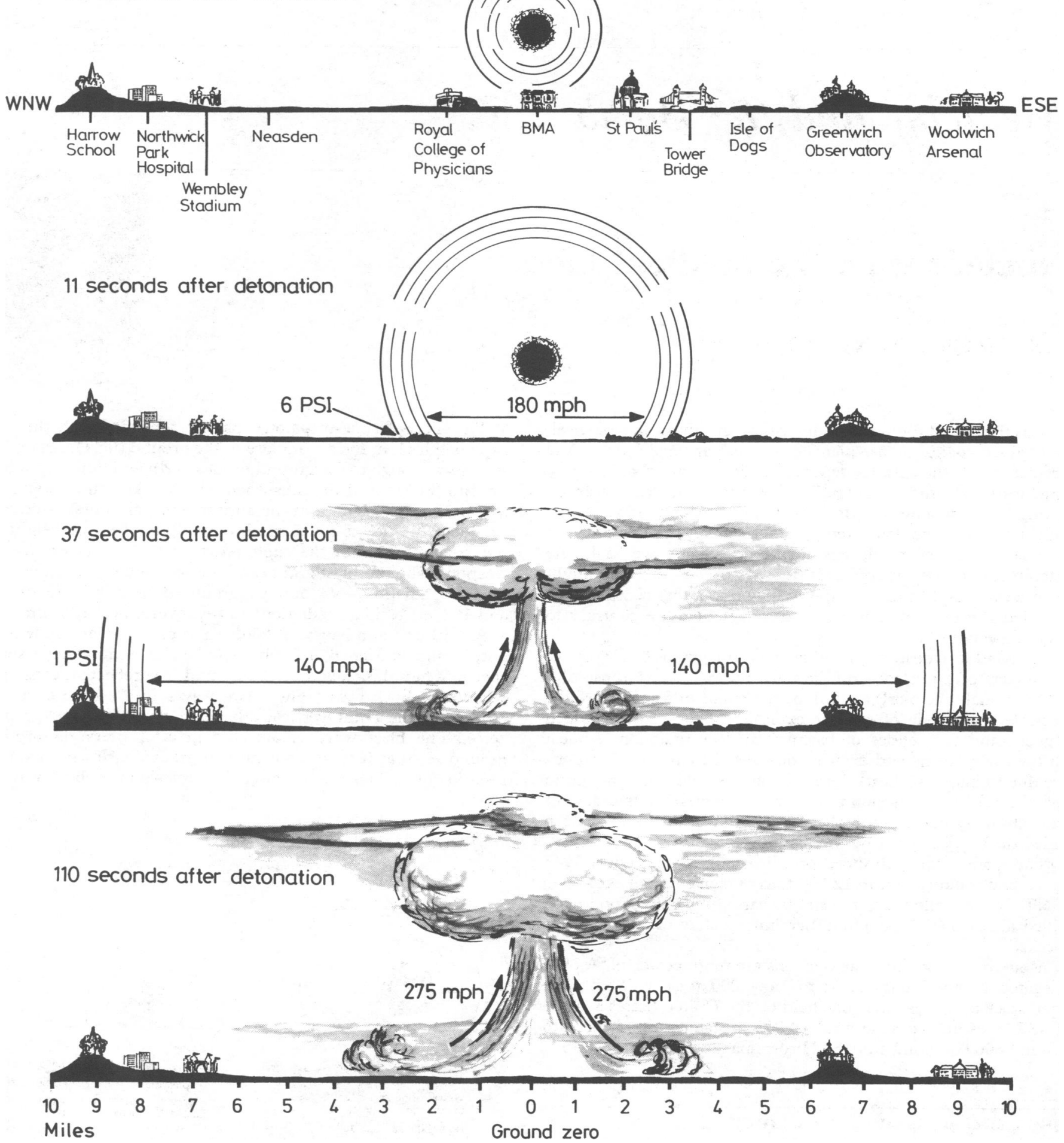

FIG 2-Effects of blast from one-megaton nuclear bomb detonated 6500 feet over BMA House in London.

PSI $=$ Pounds per square inch. 


\section{Nuclear explosions}

Nuclear fission is the splitting of the nuclei of heavy atoms such as uranium. Nuclear fusion is the combination of light atoms such as hydrogen. In both processes part of the mass of these elements is converted into energy (Einstein's equation, $\mathbf{E}=\mathbf{M c}^{2}$ ), which is released as heat and the emission of neutrons and gamma-rays of a wide range of energies. The capture of neutrons in matter reproduces the process used in radiation laboratories for manufacturing radioisotopes: the neutrons convert the elements with which they collide into radioactive isotopes.

Explosion of a uranium or plutonium bomb produces a large number of different kinds of radioactive substances, which undergo a sequence of changes into other radioactive substances. These substances are carried up with the fireball in the first seconds after the explosion, but as the fireball expands and cools its contents of radioactive particles are distributed as fallout. After an air burst they stay in the troposphere and stratosphere until local weather conditions, particularly for the troposphere rain, cause them to descend. Stratospheric dust may remain in the atmosphere for several years. Around $80 \%$ of the residual radiation produced by a surface burst is deposited locally (within 24 hours); the rest is distributed more widely as tropospheric and stratospheric fallout.

burst which does not touch the ground at all produces no local fallout particles, though neutrons released at the explosion may induce radioactivity in the ground immediately below.

A surface burst, on the other hand, draws up to thousands of tons of earth, dust, and debris into the fireball; this dust is rendered radioactive by the neutrons emitted by the bomb and by trapping fission products and descends as local fallout because the particles are large, like fine sand. Much smaller particles rise into the upper atmosphere, from which they descend only gradually. This is also true of radioactive fission products, which arrive in the troposphere or stratosphere depending on the power of the weapon.

\section{Blast}

Blast (from whatever source) damages solid structures such as buildings more easily than human bodies. Multistorey brick and timber buildings are particularly susceptible to blast; a megaton explosion will destroy all such buildings within a radius of three to four miles, but reinforced concrete buildings are more resistant. Less extensive damage to windows and roofs will be evident over a much wider area. The blast effects of large weapons are "wasteful" in the sense that the yield of a bomb has to be raised by a factor of 10 to double the diameter of the zone of destruction. A blast wave that causes a rise in the atmospheric pressure of five pounds per square inch will damage most buildings beyond repair. In a typical city environment the collapse of buildings, flying debris, and consequential fires in the area subiectcd to a pressure of five pounds per square inch or more would cause fatal injuries among most of the inhabitants (as happens in an earthquake). The "lethal area" at both Hiroshima and Nagasaki - the area with a $90 \%$ mortality rate-corresponded to the zone within which the overpressure rose by five pounds per square inch. In these cities, however, most of the buildings were wooden; the reinforced concrete structures of Western cities can withstand greater pressures and would be expected to protect some of their inhabitants against blast.
Classically, blast damages the lungs and the eardrums-but such injuries were rare at Hiroshima, because most people close enough to the bomb to have suffered such injuries were killed by fire or the collapse of destroyed buildings. Blast may, however, cause traumatic injuries to anyone in the open as far as four miles from a one-megaton explosion simply by the body being thrown about by the pressure wave-that is, within the area where pressures reach five pounds per square inch or more.

\section{Heat}

The fireball of a one-megaton bomb reaches peak intensity after about one second; with a 10-megaton device the peak is reached after about three seconds. Thermal radiation is transmitted along the line of sight-so that (as we all discover when standing around a fire) any object between an individual and the heat source acts as a shield. In theory anyone looking directly at the fireball could be blinded in the same way that people burn their retinas looking at eclipses of the sun. In practice the blink reflex seems to protect the eyes effectively. Anyone with skin exposed to the direct line of the fireball will, however, receive second-degree burns at a range of nine to 10 miles (on a clear day). Anyone inside a building would be protected, and even a single layer of clothing would provide considerable or complete protection. Within a smaller range-of about six to seven milescombustible materials such as paper, clothing, leaves and grass, and curtains may be ignited.

A possible result of a nuclear explosion in any environment other than non-combustible desert is a firestorm. At Hiroshima the firestorm lasted for six hours after the explosion, destroying nearly five square miles of the city. Within this area the fire is selfperpetuating, with a powerful vertical upstream of heated air drawing in cool air from the periphery until everything combustible has been consumed. Temperatures may exceed $1000^{\circ} \mathrm{C}$-high enough to melt glass and metal and burn materials commonly thought to be fireproof. Nevertheless, the development of a firestorm is unpredictable-depending on the combustibility of materials and the effects of the blast (which may blow small fires out): Hiroshima suffered a firestorm; Nagasaki did not.

There can be no effective shelter within the zone of a firestorm - unless the shelter accommodation is deep below ground with an independent stored air supply. Even shelters with an independent atmosphere would be covered with heated rubble for many days after the fire. The greatest firestorm of the second world war was at Dresden, where the fires were caused by conventional incendiary bombs. More than 100000 people were killed; no one survived in the deep shelters, exposed as they were to both intense heat and noxious gases.

\section{Radiation}

Radiation may conveniently be considered as either initial (within one minute of the explosion) or residual. Initial radiation is emitted at the explosion. Residual radiation is emitted from fission products and debris rendered radioactive either on the ground or by being sucked up into the air; the latter descends as early (within 24 hours) or delayed fallout. Different types of nuclear weapons produce different mixes of the same types of radiationneutrons, $x$-rays, gamma-rays, and alpha- and beta-particles. The Hiroshima bomb released proportionately more neutrons than the Nagasaki bomb (in both gamma-rays predominated). Dose for dose neutrons are more damaging than gamma-rays but travel much less far. Both are emitted at the moment of explosion, and-like the thermal radiation-the range of the effects of this initial radiation depends on the height at which the explosion occurs and on the shielding effects of buildings and hills. The amount of gamma-radiation falls off according to the square of the distance from the source combined with the effects of absorption in the material through which it travels.

Energy absorption from radiation reaching the body is almost 
instantaneous but with a one-megaton bomb, where the radiation emitted increases with time after the explosion, there are 20 seconds from the time of the flash to take cover. With bombs of one megaton and larger the quantities of radiation lethal to man are not found beyond the lethal area of blast and fire, so deaths from prompt radiation will be few after a megaton explosion. As bombs get smaller the ratio of radiation emission to blast and heat progressively increases-the principle underlying the "neutron bomb." But when the power is so small that the lethal amounts of radiation are found beyond the area of lethal blast the overall area affected is relatively small-under a mile in radius.

Any nuclear explosion creates a whole range of radioactive isotopes. These are determined by the material the bomb itself was made of, any radioactivity induced in material on the ground by neutrons emitted in the explosion, and (in the case of a surface burst) the earth, rock, and debris drawn into the fireball and mingled with the fission products. The chemical composition of the material which absorbs neutrons determines the particular isotopes produced.

\section{Distribution of fallout}

The mixture of fission products is carried up in the familiar "mushroom" cloud. After a surface burst the heavier particles of dust and debris sucked up from the ground and rendered radioactive in the fireball will descend to earth as early fallout within the 24 hours after the explosion. The pattern of fallout varies with the direction and speed of the wind, but assuming a wind with little change in direction the dust would descend in a cigar-shaped cloud with one end near the burst point. The distance from ground zero and the length and width of the "cigar" would depend on wind speed. Rain falling shortly after an explosion would bring some of the radioactive particles down to the surface and create "hotspots," where radioactivity is much higher than in surrounding areas. The timing and intensity of the radiation vary with distance from ground zero and the size of the bomb. After the detonation of a 15-megaton weapon on Bikini Atoll in 1954 very close to the ground fallout affected a cigar-shaped area extending 20 miles upwind and 350 miles downwind and up to 60 miles wide, an area of about 7000 square miles. It took 10 hours to reach the extremity of the cigar and by that time the fallout cloud had dissipated and was no longer

\section{Measuring radiation}

In the immediate surge of initial radiation from the explosion neutrons and gamma-rays are particularly important. Neutrons travel a relatively short distance compared with gamma-rays and quickly disappear after the initial surge of radiation. In the local fallout, too, penetrating gamma-rays account for all practical purposes for the damage caused by whole-body irradiation for people under cover. Those in the open may suffer surface damage from isotopes emitting betaparticles-hence the beta-burns caused to the skin of Rongelap natives after the Bikini explosion. For these articles we shall therefore concentrate on gamma-rays and express radiation in roentgens-a measure suitable for $x$-rays and gamma-rays. The effect on the human body is related to the amount of energy absorbed in tissue as a result of exposure to radiation, and this is measured in rads. In tissue near to or at the surface of the body an exposure to one roentgen results in an absorption of about one rad-equivalent to 100 ergs/gram.

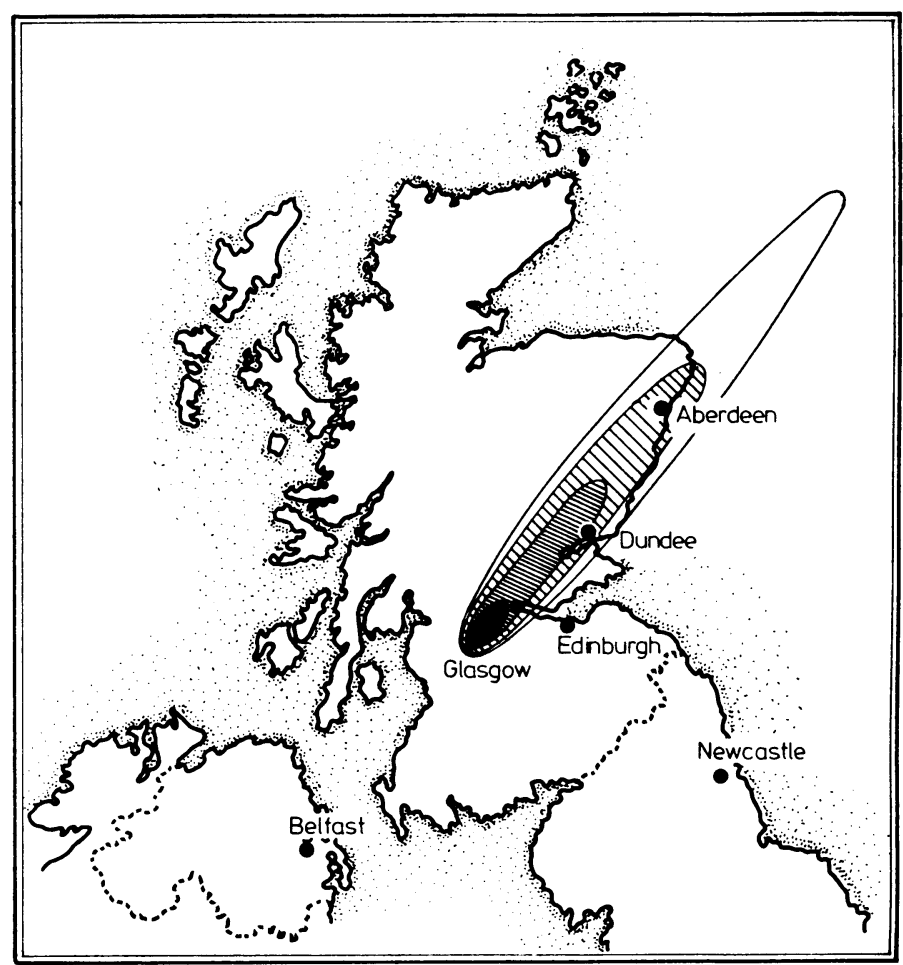

FIG 3-Fallout pattern after one-megaton surface burst on Glasgow assuming uniform south-westerly wind of $15 \mathrm{mph}$. The contours indicate seven-day accumulated doses of $3000,900,300$, and 90 rads to unprotected people. A dose of 450-500 rads will kill about half those exposed to it.

visible. In the area of higher concentration, however, nearer the explosion, the particles will be visible-as fine sand.

The finest particles are carried high up into the upper atmosphere. Those that enter the troposphere travel round the world in temperate latitudes mostly in the same hemisphere in about 12 days so that any given area in which bombs have exploded will not start to receive tropospheric fallout until 12 days have elapsed. Stratospheric particles may not start to descend for several years and only a fraction will descend in the other hemisphere. The radioactive isotopes produced by an explosion have varying half lives. Those with short half lives are obviously more important in local fallout than in long-term atmospheric fallout.

After a typical nuclear explosion the radiation dose from fallout decays according to the $t^{-1 \cdot 2}$ formula: the radiation intensity existing one hour after a nuclear explosion will decline by a factor of 10 for every sevenfold increase in time. If at one hour the intensity of radiation exposure from fallout is 3000 roentgens per hour, the rate at seven hours will be 300 roentgens, and at 49 hours $(7 \times 7)$ it will be 30 roentgens an hour and so on.

After a one-megaton surface explosion with a uniform wind of 15 miles per hour the fallout finger-that area which would expose an unprotected individual to a cumulative dose of 300 roentgens in the first seven days after the explosion-would be about 150 miles long and 20 miles wide (fig 3 ). In practice wind speed may not be this uniform, and the only way of determining whether an area has been subjected to fallout is to measure the radiation.

In summary, the effect of a one-megaton explosion would be total destruction by blast and fire within a circle about nine miles in diameter. The initial radiation emitted by the explosion, whether neutrons or gamma-rays, would not extend outside this zone in sufficient intensity to be lethal. If the bomb were detonated near the surface fallout in the immediate vicinity of the burst and downwind for as far as 150 miles would, however, expose unprotected survivors to substantial doses of radiation, though protected ones could survive.

Next week's article describes acute radiation injuries and their treatment. 